\title{
The Drivers of Firm Growth: Firm Size Effect
}

\author{
Yuyang Wang ${ }^{1}$
}

\begin{abstract}
This paper discusses an important economic problem which is why and how firms grow and argues that firm size is one of the leading contributors to firm growth discrepancy. We demonstrate the importance of firm size through the analysis of 40 years of Compustat individual firm level data. Our results indicate that despite many business advantages large firms have, smaller firms in the same industry still find their edges in growing their business.

JEL classification numbers: B410, C020, C180, C510, C520, C550, L110, L250. Keywords: Firm strategy, Firm growth, Firm size, Firm size distribution, Gibrat's law.
\end{abstract}

${ }^{1}$ Department of Science, Rensselaer Polytechnic Institute, Troy, US

Article Info: Received: September 23, 2020. Revised: October 24, 2020.

Published online: November 5, 2020. 


\section{Introduction}

For several centuries, with the continuous development of technology and society, technology has promoted the continuous development of human society. With the development of society, more and more new industries have been born. There are more and more firms in each industry, and the competition between firms is becoming more and more fierce. There are not only big firms with abundant resources, but also small firms with innovative ideas. The whole industry is developing under their joint promotion. Especially in the past decade, we have witnessed the birth of many super large firms, such as apple and Huawei in the technology industry, and Amazon and Alibaba in the e-commerce industry. Whenever talking about these firms, people will sigh at their rapid development and their leading position in the industry. The huge scale of the firm and its large amount of business need commensurate resources to support it. Without exception, they have a large number of national policies and capital support, which seems to let them on the road of continuous development unimpeded. But those small firms will face many difficulties, they do not have the resources and capital support of large firms. As a result, many people believe that unless they encounter special opportunities, they will not be able to match the growth rate of these large firms. While it may seem obvious that the business advantages of large firms would help them to grow fast, it is actually exaggerated due to the influence of many different factors, such as the exposure rate, the media will be more inclined to report the news of large firms. When people frequently see a firm's advertisements, endorsements or news, they will feel that the firm is running well and flourishing. There are paper [6] discussed this phenomenon that the firm size has significant effect towards Corporate Social Responsibility disclosure. This shows the more extensive disclosure of Corporate Social Responsibility. Because large companies have a lot of entities highlighted by the market and the public in general. On the other hand, there are many unknown firms are experiencing unprecedented rapid development; they are not large-scale but strive to innovate and they have a good atmosphere that large firms do not have, and employees are working hard for the development of the firm. Through detail empirical analysis, we will see some small firms have faster growth rate compare to the large firms. We also discuss what contributes to the success of these smaller firms in the next section.

\section{Data process and analysis}

There is a common idea that firm growth is characterized by a predominant stochastic element, making it difficult to predict [10]. Indeed, previous empirical research into the determinants of firm growth has had a limited success. For making a better research, we employ the dataset Compustat; Compustat gives a comprehensive view of all those US firms in different industries. We can directly observe how a firm grows year by year, and know when it enters and exits its industry. We focus on exactly six industries: Mining, Construction, Manufacturing, Infrastructure, Trade and Service. For better control our observants, we limit the 
range of our data from 1988 to 2018, delete those firms which do not have R\&D expenditure for all their appearance and drop those firms with missing employment data. While doing the statistical summaries, we winsorize the data between $2.5 \%$ and $97.5 \%$ by sectors to remove the effect of outliers. Besides analyzing firms from all six different industries, we also analyze firms inside each industry by quartiles. On the first stage, we divide firms to four equally-sized groups and do the statistics.

Table 1: Summary of industries

\begin{tabular}{|c|c|c|c|c|c|}
\hline \multicolumn{6}{|c|}{ Statistics of 1988-2018 Sample } \\
\hline & \multicolumn{2}{|c|}{ Employment } & R\&D/Sales & Sales Growth & Emp Growth \\
\hline Quartile & Mean & Max & Mean & Mean & Mean \\
\hline 1 & 30 & 79 & 7.83 & 0.78 & 0.09 \\
\hline 2 & 197 & 390 & 0.95 & 0.39 & 0.16 \\
\hline 3 & 1180 & 2777 & 0.11 & 0.20 & 0.14 \\
\hline 4 & 30318 & 315889 & 0.05 & 0.10 & 0.06 \\
\hline
\end{tabular}

Table 1, gives us a detailed summary of all those industries. We observe that firms in the first quartile have the highest $R \& D$ to Sales ratio and Sales growth rate, while firms in the second quartile have the largest employment growth rate.

Table 2: Manufacturing and Service sectors

\begin{tabular}{|c|c|c|c|c|c|}
\hline \multicolumn{3}{|c|}{ Statistics of 1988-2018 Sample } & \multirow[b]{2}{*}{ Sales Growth } & \multirow[b]{2}{*}{ Emp Growth } & \multirow[b]{2}{*}{$\mathrm{N}$} \\
\hline & Employment & R\&D/Sales & & & \\
\hline Group & Mean & Mean & Mean & Mean & \\
\hline Mining & 10373 & 0.11 & 0.18 & 0.06 & 2,100 \\
\hline Construction & 2937 & 0.06 & 0.22 & 0.13 & 471 \\
\hline Manufacturing & 6373 & 0.82 & 0.17 & 0.07 & 69,212 \\
\hline Infrastructure & 20033 & 0.20 & 0.25 & 0.14 & 3,651 \\
\hline Trade & 8404 & 0.06 & 0.19 & 0.11 & 2,936 \\
\hline Service & 2328 & 0.29 & 0.27 & 0.14 & 20,497 \\
\hline
\end{tabular}

In Table 2, while Infrastructure and Mining sectors have the most employment, we notice that Manufacturing and Service sectors have the highest R\&D intensity.

To establish a criterion of 'small firm' in our research, we defined that the smallest $25 \%$ firms as 'small firm', which we found out to be firms whose employees was less than 79 .

We want to make sure that the criteria of small firms will not change much over 
time, that we select five years data within a period of 20 years to observe the firm size distribution over time. See Figure 1, we find that though large firms grow larger, firm distribution stays comparatively constant over time.

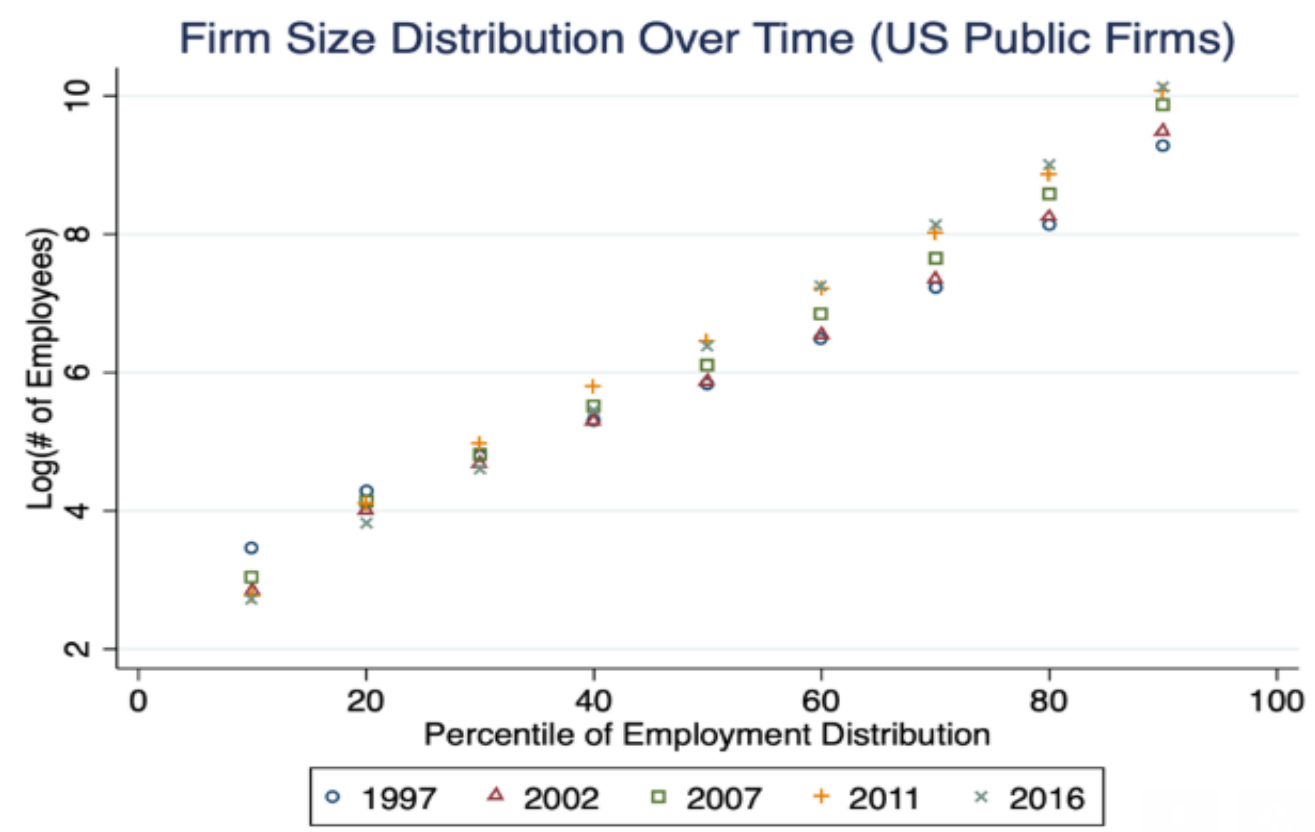

Figure 1: Firm size distribution over time

Since the firm size distribution is quite stationary, we pool all the data and use the quantiles of the pooled size distribution. On the second stage, we examine the relationship between firm size and firm growth rate. 


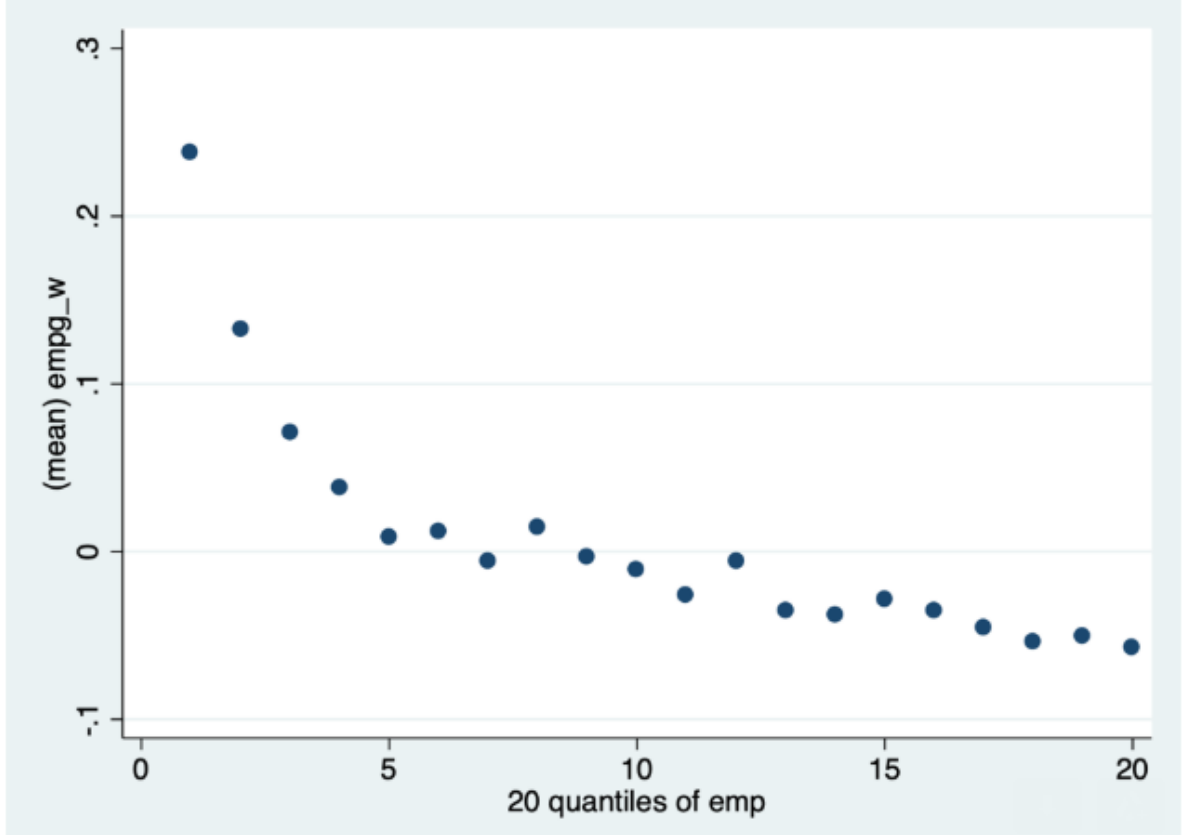

Figure 2: Relation firm size and firm growth

Table 3: Regressions of different time periods

\begin{tabular}{lcccc}
\hline & $(1)$ & $(2)$ & $(3)$ & $(4)$ \\
VARIABLES & $1988-2018$ & $1988-2000$ & $2000-2006$ & $2007-2018$ \\
\hline log employment & $-0.0313^{* * *}$ & $-0.0465^{* * *}$ & $-0.0376^{* * *}$ & $-0.0111^{* * * *}$ \\
& $(0.00171)$ & $(0.00289)$ & $(0.00355)$ & $(0.00223)$ \\
Constant & $0.209^{* * *}$ & $0.367^{* * *}$ & $0.247^{* * *}$ & -0.00565 \\
& $(0.0122)$ & $(0.0205)$ & $(0.0256)$ & $(0.0169)$ \\
Observations & & & & \\
R-squared & 98,027 & 40,872 & 25,946 & 31,209 \\
Sector-Year Controls & 0.082 & 0.047 & 0.036 & 0.192 \\
\hline
\end{tabular}

Robust standard errors in parentheses

${ }^{* * *} p<0.01,{ }^{* *} p<0.05, * p<0.1$ 
From the plot of Figure 2, we can find a negative relation between firm size and firm growth, which shares a same idea with other paper's idea[3] that they concluded that small retail firms tended to grow faster than large ones in a large majority of retail industries. Some other researchers also imply that there is a positive and robust association between average firm size and growth [5]. What's more, many other examined the relationship between a firm's size and its growth rate within the U.S domestic and international restaurant firms[4]; They found that U.S restaurant firms have a negative relationship between firm size and growth rates either, suggesting a very same idea as of our research. We make our model

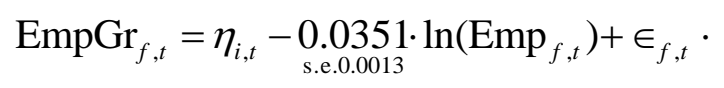

and then, by running regressions of different time periods, in Table 3, we confirmed that small firms grow faster than larger firms and it is relatively stable over time. In this often-studied topic, we share some idea with [1] that small firm grow faster, yet in some particular time periods, there is no difference in the growth rates of small and large firms. Here, we share a different idea with [2] that Gibrat's law says firm's growth in value is proportional to its size, and thus firm's growth rate $=$ growth amount/size should be independent of its size. The empirical literature dealing with corporate growth likes [9] does not in general give support to Gibrat's Law stating that the expected increase in firm size is proportionate to its initial size, leaving their growth rates independent of size. In our model, if Gibrat's law holds true, the coefficients of "lnemp" should be zero but not tend to be zero in our regression. We can observe that the coefficient of "log employment" becomes closer to 0 during 2007-2018. In column (2) from 1988-2000, the coefficient is -0.0465 , which is the highest among the three periods we have here. It changed to -0.0376 for $2000-2006$, and then to -0.0111 in 2007-2018. For this point of view, the findings in paper supports the hypothesis that any general conclusion concerning Gibrat's Law cannot be reached without considering heterogeneity, at least among firms of different industries [8]. From our result, there are many reasons responsible for the change in this coefficient: the Doc-com Bubble between 1995 to its peak in March 2000, the Late-2000s recession, the United States housing bubble and United housing market correction during the year 2003 to 2011, and the automotive industry crisis of 20082010. All of those tend to drive the coefficient to 0 . There are paper which supports our result that they used data collected from the database Albertina CZ Gold Edition to reject the Gibrat's law that they used three different indicators for measuring firm size and Gibrat's law is rejected for all three indicators of firm size [7]. 
Table 4: Differences in coefficients

\begin{tabular}{|l|c|c|}
\hline & $(1)$ & $(2)$ \\
\hline VARIABLES & $2007-2012$ & $2013-2018$ \\
\hline lnemp_w & & \\
\hline Constant & $0.0080^{* * *}$ & 0.0010 \\
\hline & $(0.00114)$ & $(0.00130)$ \\
\hline & 0.0313 & $-0.0607 * *$ \\
\hline Observations & $(0.03789)$ & $(0.03019)$ \\
\hline R-squared & & \\
\hline Sector-Year Controls & 16,632 & 12,856 \\
\hline
\end{tabular}

Robust standard errors in parentheses $* * * \mathrm{p}<0.01, * * \mathrm{p}<0.05,{ }^{*} \mathrm{p}<0.1$

See Table 4, we break 2007-2018 into 2007-2012 and 2013-2018 to find out the difference in coefficients for each five-year period. The result shows the coefficients' trends to be 0 . Which can be explained separately by the Global Economic Crisis and its continued impact on the economy. During these periods, for those small firms in industries, the recession forces them to encounter a reduced cash flow, loss of demand, staffing reduction and marketing constraints. The small firm faces much more obstacles compared to large firms.

Also, to ensure the result is not just correlation but causality, we took some tests for robustness. In our data cleaning process, we set a firm employment growth rate to 1 when a firm exits the sample data, meaning that a firm laid off $100 \%$ of its employees before exiting. However, in fact, a firm may only lay off $10-20 \%$ of the work force, and then exit. So, setting them to be -1 overestimates the actual growth rate. Since small firms are more likely to exit, this overstates the reduction rate for small firms and penalizes small firm growth rates. There may be some factors that will cause this bias, for example, firms with higher leverage are more likely to exit. In our research, we assume total long-term debt issued and short-term debt issued as two factors that have influence on firm exits. Employing the method of Heckman two-step estimation, we have the regression result on Table 4. 
Table 5: Negative coefficients

\begin{tabular}{|c|c|c|c|c|}
\hline & (1) & (2) & (3) & (4) \\
\hline VARIABLES & Baseline & Heckman & Heckman & IV \\
\hline \multirow[t]{2}{*}{ log employment } & $-0.0313^{* * *}$ & $-0.0212^{* * * *}$ & $0.107^{* * * *}$ & $-0.0427^{* * *} *$ \\
\hline & $(0.00171)$ & $(0.00187)$ & $(0.00520)$ & $(0.00183)$ \\
\hline \multirow[t]{2}{*}{ logdltt } & & & $-0.0138^{* * *}$ & \\
\hline & & & $(0.00391)$ & \\
\hline \multirow[t]{2}{*}{$\log d d 1$} & & & $-0.0492^{* * *}$ & \\
\hline & & & $(0.00418)$ & \\
\hline \multirow[t]{2}{*}{ Mills } & & $0.700^{* * * *}$ & & \\
\hline & & $(0.09878)$ & & \\
\hline \multirow[t]{2}{*}{ Constant } & $0.209^{* * *}$ & -0.0996 & $0.666^{* * *}$ & $0.243^{* * *}$ \\
\hline & $(0.0122)$ & $(0.220)$ & $(0.0292)$ & $(0.0705)$ \\
\hline Observations & 98,027 & 60,700 & 60,700 & 98,027 \\
\hline R-squared & 0.082 & & & 0.081 \\
\hline Sector-Year & $\mathrm{Y}$ & $\mathrm{Y}$ & $\mathrm{Y}$ & $\mathrm{Y}$ \\
\hline \multicolumn{5}{|l|}{ Controls } \\
\hline Instruments & & & & $\mathrm{Y}$ \\
\hline
\end{tabular}

Robust standard errors in parentheses

$* * * p<0.01, * * p<0.05, * p<0.1$

The mills is significant, so the bias exist. As a result, we need to introduce dltt and dl1 to evade bias. Further, we also want to control for measurement error. Since employment appears both in the regressors and denominator of the left- hand size variables, a measurement error can generate spurious negative association between size and growth rate and would error, which would bias the estimate downwards. To test this, we employ test for Instrumental Variables. For all our IVs regression, we also use cluster robust standard errors and cluster at the firm level. See Table 5, we find the coefficients become more negative, which also confirms the measurement error conjecture.

\section{Conclusion}

From all the above analysis, we get to the conclusion that small firms grow faster. Though data show us this result, some people may think different; Since small firms don't have as much capital and resource as large firms, they probably believe that those small firms wouldn't be able to get much bank loan or other support for developing. However, government has a series of program to help those small firms to grow and there are many related law to protect small firms' advantages. Thus, our research result is supported not only from data, but also from the society aspect. 


\section{References}

[1] Ufuk Akcigit and William R. Kerr, 2018. "Growth through Heterogeneous Innovations," Journal of Political Economy, vol 126(4), pages 1374-1443.

[2] John Sutton. Gibrat's Legacy, Journal of Economic Literature, Vol. 35, No. 1 (Mar., 1997), pp. 40-59

[3] Daunfeldt, Sven-Olov \& Elert, Niklas. (2011). When is Gibrat's Law a Law? Small Business Economics. 41. 10.1007/s11187-011-9404-x.

[4] Park, and Sydnor (2011). The Validity of Gibrat's Law in Developed and Developing Countries (2008-2013): Comparison based Assessment.

[5] Patrizio Pagano and Fabiano Schivardi, 2001. "Firm Size Distribution and Growth," Temi di discussione (Economic working papers) 394, Bank of Italy, Economic Research and International Relations Area.

[6] Waluyo Waluyo, 2017. "Firm Size, Firm Age, and Firm Growth on Corporate Social Responsibility in Indonesia: The Case of Real Estate Companies," European Research Studies Journal, European Research Studies Journal, vol. 0(4A), pages 360-369.

[7] Roman Fiala and Veronika Hedija, 2015. "The Relationship Between Firm Size and Firm Growth: The Case of the Czech Republic," Acta Universitatis Agriculturae et Silviculturae Mendelianae Brunensis, Mendel University Press, vol. 63(5), pages 1639-1644.

[8] R. Piergiovanni and E. Santarelli \& L. Klomp \& A.R. Thurik, 2002. "Gibrat's Law and the Firm Size / Firm Growth Relationship in Italian Services," Tinbergen Institute Discussion Papers 02-080/3, Tinbergen Institute.

[9] Jan Bentzen and Erik Madsen \& Valdemar Smith, 2012. "Do firms' growth rates depend on firm size?," Small Business Economics, Springer, vol. 39(4), pages $937-947$, November.

[10] Alexander Coad, 2007. "Firm Growth: A Survey," Papers on Economics and Evolution 2007-03, Philipps University Marburg, Department of Geography. 